\title{
Notas SOBRE A PRESENÇA NORDESTINA EM RORAIMA ${ }^{1}$
}

\section{Carla Monteiro de Souza ${ }^{2}$, Francisco Marcos Mendes Nogueira ${ }^{3}$}

RESUMO: A Amazônia Brasileira é um lugar de migrantes, de muitos e diferentes que buscam na região o sonho mítico do paraíso e da terra das riquezas sem fim. Assim como em outras áreas amazônicas, os migrantes que chegam à Roraima são motivados por circunstâncias diversas, marcadas por conjunturas sócio econômicas que historicamente aproximam as regiões Nordeste e Norte. O movimento constante de entrada de nordestinos na Amazônia e em Roraima enseja trocas culturais e engendra modos de viver e de significar a experiência migratória e de inserção, que se manifestam em variadas práticas e se nos apresentam sob as mais diversas formas de expressão. Este trabalho pontua discussão a presença nordestina em Roraima, a partir de algumas aproximações possíveis: Nordeste/Nordestes, Nordeste/Amazônia, Nordeste/Roraima. Neste sentido, apresenta uma leitura do cordel "Roraima terra bendita" (2009), da autoria de Otaniel Mendes de Souza, um maranhense radicado em Roraima desde 1982.

PALAVRAS-CHAVE: Roraima. Amazônia. Literatura de Cordel. Migrantes. Nordeste.

O poeta roraimense Eliakim Rufino em uma de suas composições afirma que "quem é filho do Norte é neto do Nordeste". Em versos inspirados, o autor apresenta uma série de metáforas e referências identitárias que dão sentido a esta enfática afirmação: Sou chuva na floresta/Sou mandacaru do agreste; Sou farinha de caboclo/Eu sou cabra da peste. De forma poética e alegre, o autor entrecruza as várias origens e um destino, que entrecruzam os vários Nordeste e o Norte, e que nos remete ao cotidiano roraimense e à composição da sociedade local, historicamente marcada pela presença do migrante, pelos múltiplos de encontros/desencontros, pela pluralidade de influências na sua constituição, na qual a presença nordestina sobressai.

A beleza da canção e o fato de estar muito bem referen-

\footnotetext{
${ }^{1}$ Originalmente publicado nos Anais do XXVII Simpósio Nacional de História, Associação Nacional de História, ANPUH, realizado em Natal, Rio Grande do Norte, no período de 22 a 26 de julho de 2013.

${ }^{2}$ Doutora em História, Professora da Universidade Federal de Roraima.

${ }^{3}$ Mestrando do Programa de Pós-Graduação em Sociedade e Fronteiras da Universidade Federal de Roraima.
} 
ciada na sociedade roraimense são elementos que apontam para a importância da presença nordestina no estado, algo que parece ser algo unânime e, em certas visões, beira a naturalização. Isso nos inquieta e nos impeliu a provocar esta discussão. Este trabalho, portanto, tem como objetivo suscitar essa discussão, através da apresentação de alguns aspectos sobre a presença de migrantes nordestinos em Roraima e algumas reflexões sobre a questão.

\section{A histórica presença migrante em Roraima}

Roraima é o estado brasileiro localizado mais ao norte e que possui uma extensa fronteira internacional, com a República Bolivariana da Venezuela e a República Cooperativista da Guiana. Nesta tríplice fronteira confinam três línguas nacionais, português, espanhol e inglês, e várias línguas indígenas. A área do atual estado foi município do Amazonas até 1943, quando passou a ser Território Federal do Rio Branco (em 1962 passou a se chamar TF de Roraima), sendo transformado em estado em 1988 (BARROS, 1995; OLIVEIRA, 2003; SANTOS, 2004; SOUZA, 2001).

Localizado em uma região que ainda hoje mantém parcas ligações com o restante do país, Roraima tem a menor população do Brasil, concentrada na capital, Boa Vista. Nos 15 municípios existentes na atualidade convive uma população formada por não índios, migrantes e seus descentes, e indígenas de várias etnias. O seu perfil socioeconômico aponta para uma economia baseada no serviço público e no setor de serviços, bem como em atividades rurais, como a pecuária, as lavouras de produtos alimentícios e a produção de subsistência (http://www.seplan.rr.gov.br). Neste contexto, historicamente o poder público e as iniciativas e ações governamentais exercem um forte papel, inclusive no que diz respeito ao povoamento e às migrações, características estas compartilhadas com os demais estados amazônicos.

Quanto ao povoamento da região, desde o período colonial o governo metropolitano se preocupou com a carência de população não indígena nesta porção de suas possessões amazônicas. A instalação do Forte de São Joaquim e das Fazendas Reais de São Marcos, São José e São Bento, no final do século XVIII e início do XIX, inauguram estas ações que visavam incrementar o povoamento da região. Nos séculos XIX e XX, notadamente, nos dois períodos 
de auge da extração de látex - Ciclo da Borracha (1870-1920) e a Batalha da Borracha (meados da década de 1940) - observa-se um incremento das migrações para a Amazônia, atingindo timidamente Roraima. Ainda que não se observe a ocorrência da extração intensiva de borracha na região do Rio Branco, esta recebeu migrantes por tabela, fruto dos deslocamentos dentro da própria região decorrentes da decadência desta atividade (MAGALHÃES, 2008).

A leitura dos cronistas e viajantes que percorreram a região amazônica desde o período colonial, bem como estudos e dados mais recentes (como, por exemplo, os estudos do IPEA, do CEDEPLAR e do IBGE), demonstram que as migrações inter-regionais bem como as intra Amazônias são historicamente constantes. Pesquisas anteriores nos permitem afirmar que o migrante que chega a Roraima, em muitos casos, é o que denominamos migrante por etapas, isto é, percorre e vive em outras áreas, inclusive da própria Região Norte antes de se estabelecer no estado (SOUZA, 2001; 2006). Assim, não é raro encontrar nordestinos que experenciaram a vida em outras frentes de expansão amazônicas antes de fixarem residência em Roraima.

Por outro lado, a análise sobre o povoamento da região realizada em uma perspectiva multidisciplinar nos permite afirmar que existe uma relação de complementaridade e interação entre a Região Nordeste e a Norte, que permitiriam definir formalmente uma situação de "expulsão" para a primeira e de "atração" para a segunda. Como dito acima, conjunturas socioeconômicas em diversos períodos carrearam para a Amazônia trabalhadores oriundos de várias partes do Nordeste. São exemplos disso os períodos de auge da exploração da borracha, a abertura de estradas nas décadas de 1950 e 1960, a política de ocupação pautada no "Integrar para não Entregar" do Regime Militar ou, mais recentemente, as ações balizadas pelo conceito de desenvolvimento sustentável.

O estudo do povoamento da Amazônia e de Roraima, em especial, na sua dimensão estrutural e conjuntural, permitem afirmar que existe uma espécie de "corredor de acesso" entre as duas regiões. Verifica-se que estas rotas de passagem são condicionadas em grande parte pela expansão dos meios de transporte e de comunicação e pela quantidade e qualidade dos estímulos engendrados pela dinâmica econômica e geopolítica que historicamente visam 
ocupar o "vazio" amazônico, que findam por criar as chamadas condições de atração de nordestinos.

Fazendo uma projeção por meio da historiografia, os estudos sobre várias épocas mostram que os nordestinos há muito povoam a Amazônia e estão em Roraima desde os primórdios de sua ocupação. Neste caminho, nos deteremos na migração que liga o Nordeste à Roraima na atualidade, traçando um painel que permita dimensionar a sua abrangência e importância na sociedade local.

Nas últimas quatro décadas, segundo dados do IBGE (Censos Demográficos de 1980, 1991, 2000, 2010), boa parte dos migrantes que chegam à Roraima são provenientes da própria Região Norte (Pará e Amazonas) e, principalmente, do Nordeste, destacando-se os maranhenses. Quanto ao primeiro dado, podemos observar que muitos destes que procedem do Pará ou do Amazonas, por exemplo, ou são naturais de um estado nordestino que migram por etapas ou são descendentes de migrantes nordestinos já nascidos nestes lugares. Quanto aos provenientes do Maranhão, estes estão espalhados por toda a Amazônia, fato que pode ser explicado por sua realidade socioeconômica excludente, podendo ser arrolada também como facilitadora da migração a proximidade geográfica com o Pará e o fato de parte do território do Maranhão integrar a Amazônia Legal.

O cotejo dos dados demográficos de Roraima demonstra que a entrada de migrantes é contínua e é um elemento definidor do crescimento populacional do estado. No geral, os migrantes que vieram para Roraima nas últimas quatro décadas podem ser caracterizados como populações provenientes de áreas do interior, onde os padrões de vida tendem a ser baixos devido a fatores como a concentração fundiária, economia frágil e instável, mercado de trabalho acanhado etc. Por outro lado, é possível identificar no antigo território federal (e atual estado) nas últimas décadas alguns elementos de estímulo ao aumento populacional, tais como garimpo, facilidade de acesso à terra, no âmbito rural e urbano, montagem de uma novo estrutura político administrativa com a passagem a estado, abertura de estradas. 
Argumentamos, neste sentido, que o ato de migrar implica a interação de três planos: um fundamentado nas relações sociais, estruturalmente vinculado à fatores socioeconômicos e políticos; outro relacionado ao plano conjuntural, relacionado às políticas, programas e ações concebidas e implementadas; e outro referenciado no individual, que, em última instância, determina a decisão de migrar. Nesta seara, as migrações não podem ser tomadas como processos determinados exclusivamente pelos fatores que chamamos de estruturais, os quais nos levam a considerar que os migrantes, premidos por situações adversas em seu lugar de origem ou imbuídos de sonhos e ilusões, agiriam de forma um tanto "inconsciente", o que fundamenta a noção de "expulsão" (SOUZA, 2005).

Por sua complexidade intrínseca, acreditamos que na análise das migrações devemos considerar que a decisão pelo deslocamento envolve a ponderação de prós e contras, bem como a intensa ação das redes de contato e de informação, notadamente frente ao alargamento dos meios comunicação verificado nas últimas décadas. Neste contexto, o que um parente ou amigo migrado conta, atua como um liame, um fio que liga a situação vivida e a pretendida, bem como as flutuações conjunturais, como a ocorrência de garimpos ou a implantação de projetos e programas de colonização por exemplo. Nas entrevistas que realizamos com migrantes em vários projetos, verificamos que sonho e realidade por vezes se confundem, principalmente frente àquelas situações limite que tornam a vida insustentável, o que nos leva a considerar e valorizar as questões subjetivas, afetivas e psicológicas.

Assim, acreditamos que as especificidades de cada região conformam aos fluxos migratórios que dela saem e nela entram. Algumas historicamente se destacam por ter uma cultura migratória de saída, como o Nordeste, ou de recepção, como a Amazônia (SOUZA, 2004). Pensando neste movimento historicamente constante de sair (do Nordeste) e de chegar (no Norte), e voltando nosso olhar para Roraima, acreditamos que as migrações recentes para a região se inserem no que José de Souza Martins chama de expansão da "fronteira do humano". Como explica o autor, para entender o recente alargamento da fronteira amazônica, entendida como frente de expansão, é preciso levar em con- 
ta que "faixas" se mesclam e se interpenetram, colocando em contato populações cujas diversidades e antagonismos incluem o desencontro dos tempos históricos em que vivem. Na ocupação da Amazônia, e de Roraima em especial, além das redefinições espaciais, ocorreram e ocorrem encontros/desencontros de indivíduos e grupos dotados de temporalidades distintas e diferenciadas bagagens culturais, e é isso que desejamos pontuar.

\section{Os Nordestes na Amazônia}

Historicamente os deslocamentos dos nordestinos e a sua decantada necessidade e capacidade de migrar, independentemente do estado de origem, são tradicionalmente associados ao fenômeno da seca, seus complicadores ecológicos e econômicos. Argumentos relacionados à defasagem socioeconômica dos estados nordestinos e à predominância de práticas políticas tidas como retrógradas, paternalistas e clientelistas completam o quadro que em comparação como o Sudeste e Sul, ainda hoje atribuem ao Nordeste o rótulo de região atrasada e subdesenvolvida, lugar de mão de obra barata e desqualificada pronta para migrar. Estes argumentos tornam-se cada vez mais anacrônicos, principalmente quando analisamos dados demográficos e censitários que apontam para o incremento da migração de retorno e para os novos perfis e tendências migratórias.

No entanto, mesmos que as coisas estejam mudando, no bojo da relação centro-periferia os discursos e as práticas regionalistas instituíram uma "verdade" sobre as regiões, que permanece baseada em certos padrões, características, estereótipos, epítetos e símbolos que, se por um lado, baseiam-se em argumentos e aspecto factíveis, por outro, desfiguram-nas. Este processo de formulação e instituição das regiões está introjetado sobremaneira na sociedade brasileira, no plano coletivo, social e, também, individual. Construída historicamente, a ideia que nomeia e define cada região brasileira acaba por ser naturalizada, ainda que se operem mudanças socioeconômicas, políticas e culturais visíveis em todos os cantos do país.

A comparação entre a parte Norte e a Sul do Brasil - nomenclatura genérica que vigorava antes da atual divisão por regiões - é fundamental na compreensão da construção da ideia do Nordeste como região. Seus 
contornos remontam ao final do século XIX e início do XX, momento em que a ciência passa a ocupar lugar de destaque na explicação dos fenômenos naturais e dos processos sociais. No Brasil, a construção das ideias regionalistas foi fundamentada no discurso sobre o imperativo da modernização para romper a herança colonial e promover o progresso, e pelas disputas entre as elites políticas locais, polarizada entre republicanos e federalistas.

Um arcabouço teórico, ideológico e político ganha corpo a partir dos estudos e das obras de Nina Rodrigues, Oliveira Vianna, Lourenço Filho, Euclides da Cunha, Gilberto Freyre, dentre outros. Tratavam do tema, explicitando-o por meio de dados e argumentos, fundamentando práticas, ações e discursos, dando forma à polarização entre o Norte e o Sul que dividia o país em duas partes bem distintas. Durval Muniz, em seu trabalho clássico intitulado "A invenção do Nordeste", explica que estes novos discursos e práticas regionalistas que predominavam na década de 1920, quando o Nordeste foi instituído como região, primavam por apontar a "diferença acentuada na vida material e social" entre o Nordeste e o Sudeste/Sul, concluindo que se forjou uma ideia de que o Norte era o "outro" do Sul (ALBUQUERQUE Jr., 1999, p.43).

Segundo o autor, a influência da raça e do clima era um elemento marcante neste discurso, que se baseava no geral na relação de causalidade entre natureza e cultura. Neste aspecto, o clima quente, as secas periódicas e a forte presença de negros e mestiços determinariam fraquezas inatas: uma compleição física franzina e uma inferioridade psicológica, a predisposição aos vícios, à subserviência, ao fanatismo e á crendice, a indolência e a falta de iniciativa no trabalho. O meio e a seca eram a principal justificativa para quase tudo no Nordeste, inclusive para a propensão para migrar imputada ao homem nordestino (ALBUQUERQUE Jr., 1999, p. 38-39).

Esta lógica define muitas explicações sobre os altos índices de emigração do Nordeste, dando-lhe a consistência necessária, para que se popularize também no senso comum. A seca sempre esteve no centro destas explicações, somada à concentração fundiária, à acentuada desigualdade social e ao abandono por parte do poder público. Segundo Rogério Haesbaert, estes elementos também fundamentam as explicações do porque historicamente o mi- 
grante nordestino procura os grandes centros ou as frentes de expansão agrícola, como a Amazônia. O mito da "região-problema", segundo ele, fundamenta as explicações sobre o "fenômeno migratório", tornando-se importante referencial identificador dos nordestinos, "como se todos os nordestinos vivessem hoje, da mesma forma, as consequências da seca, ou como se todos fossem ou tivessem sido um dia 'sertanejos', 'cabras da peste"'. O migrante nordestino, portanto, acaba por ser estereotipado na figura do 'retirante' miserável da seca (HAESBAERT, 1997). No entanto, como referido acima, por mais evidentes que sejam os fatores estruturais que justifiquem uma migração, esta sempre dependerá em boa parte de um conjunto complexo de elementos - de que haja uma relação de complementaridade entre o lugar de origem e o lugar de destino - e da escolha pessoal entre partir e ficar.

A migração de nordestinos para a Amazônia ganha a característica de fluxo na época do primeiro boom da borracha e a partir daí vem se mantendo, fortemente influenciada pelos surtos econômicos característicos da região e pela ação do Estado. As possibilidades de povoamento e ocupação de Região Norte historicamente são associadas aos problemas estruturais do Nordeste. Esta construção, que vigorou ao longo do século XX e ainda tem eco na atualidade, pode ser sintetizada na máxima do presidente militar, Emílio Garrastazu Médici: "levar os homens sem terra do Nordeste para as terras sem homens da Amazônia" (OLIVEIRA, 1991). Além de povoar o "vazio" amazônico, interessava também aos planejadores e governantes da época inverter o vetor desta migração da Região Sudeste para a Norte, observando-se que os elementos citados acima permaneciam presentes e válidos.

Este discurso instituído acerca do Nordeste foi fundamental na composição e na sedimentação de uma imagem extremamente negativa para a região. Este discurso e esta imagem da região se difundiram, impregnando o imaginário coletivo nacional até os dias de hoje. No dizer de Albuquerque Jr., "o 'Norte' é o exemplo do que o 'Sul' não deveria ser", sendo o oposto da imagem elaborada do Sul civilizado. As práticas e os discursos regionalizantes que se cruzam, sejam políticos, econômicos ou culturais, sedimentam a ideia de a Região Nordeste que deixa de ser a área seca do "Norte", para se tornar-se uma 
identidade, uma parte do nacional, definida e delimitada racial, econômica, social, política e culturalmente (ALBUQUERQUE Jr., 1999). Longe de uma perspectiva determinista e simplificadora e buscando recurso no binômio identidade/ alteridade, a imagem de superioridade do "Sul" implicaria na inferioridade do "Norte", que naturalmente ficará sempre para trás.

\section{Os Nordestes em Roraima}

Em Roraima, os nordestinos sempre desempenharam papel fundamental na configuração da sociedade local. Destaca-se, entretanto, que ainda há poucos estudos que fazem distinção entre as migrações provenientes dos vários estado do Nordeste. Nos estudos sobre a questão prevalece o uso da categoria englobante "nordestinos" e, aqui, mesmo sabendo dos sérios riscos das generalizações, também falar-se-á em presença e cultura nordestina.

Para isso, tomamos como referência o estudo mais recente de Albuquerque Jr. que, se referindo à ideia da existência de um folclore nordestino e de uma cultura nordestina, afirma que os mesmos se tornam "uma verdade inquestionável, um fato do qual ninguém escapa", a partir de vários fatos ocorridos entre os anos 1920-30, nos quais há "uma verdadeira genealogia de atitudes, práticas, ditos, escritos que vão" dando forma ao folclore e a cultura do Nordeste (ALBUQUERQUE Jr., 2013, p. 116). Ainda sobre isso, a discussão apresentada pelo geógrafo Rogério Haesbaert sobre a construção de uma "identidade nordestina", baseia-se no que define como "transposição geográfica", explicando que a identidade nordestina construída a partir de imagens do sertão semiárido, transforma o "sertanejo" em "nordestino". Neste sentido, o sertanejo habitante do semiárido e da caatinga passa a definir a população daquela região do Brasil, ao ser alçado a condição de elemento central na construção simbólica do "ser" nordestino, ainda na virada do século XIX para o XX. Por outro lado, a "descoberta" da seca e a sua "institucionalização" - com a criação do Departamento Nacional de Obras contra a Seca (DNOCS) e depois da SUDENE, a definição do "Polígono das Secas" - junto à divulgação do flagelo vivido por sua população, servirão para projetar o semi-árido como principal elemento caracterizador da identidade nordestina (HAESBAERT, 1997, p. 72-84).

Segundo o autor, esta identidade tem um caráter extre- 
mamente ambíguo, já que "está presente muito mais no discurso da elite política e da burguesia regional", expandindo-se para fora da região e configurando a "mentalidade" dos que convivem com "migrante nordestino", do que entre a maioria da população local, que se identifica muito mais com seu estado de nascimento (HAESBAERT, 1997, p. 72-84). Esta identidade nordestina homogeneizadora e englobante, portanto, não dá conta das múltiplas referências culturais e identitárias vivenciadas e ressignificadas cotidianamente pelos sujeitos que vivem na região e pelos que migram.

Contudo, não se pode negligenciar que o Nordeste e o "nordestino" são construções bastante sólidas e que se perpetuam por meio de uma série de mecanismos de divulgação e de atualização. O nordestino popularizado pelas mídias de massa tem um sotaque padronizado, apresenta uma série de comportamentos e certas características marcantes, uma espécie de sertanejo standartizado, um tipo que passa a ser associado a certas coisas muito peculiares. As manifestações culturais e identitárias nordestinas seguem algumas rotas e se constituem por meio de formas socialmente consolidadas dentro e fora daquela região, que se tornam marcas, rótulos, diacríticos reconhecidos da forma de ser e viver dos naturais do grande e diverso Nordeste.

A migração nordestina foi e é responsável por grande parte das mudanças espaciais e sociais ocorridas em Roraima, inclusive as mais recentes. Segundo Vale, "como bom migrante que é, desbravador de fronteiras", o nordestino foi responsável pela produção do espaço de grandes áreas do Brasil (2001), no extremo norte do país não foi diferente.

Em Roraima, além de sua histórica participação nas lides pecuárias, a presença do migrante nordestino moldou, sobremaneira, a sociedade regional. As paisagens naturais e culturais estão impregnadas por elementos culturais de origem nordestina, esta tomada como categoria englobante. Está nos hábitos alimentares, nas devoções e festividades, no linguajar, nos usos e costumes, sendo que muitos nordestinos dizem se sentir em casa em Roraima. Pode-se afirmar que a população nativa, notadamente os de origem indígena, absorveu e incorporou as influências nordestinas. Da mesma forma, os sinais de sua prevalência estão por toda parte, fato que lhes confere certa notoriedade em relação aos outros grupos migrantes. 
A representatividade dos nordestinos e seus descendentes na sociedade regional podem ser avaliadas através de dados demográficos históricos e atuais. Além de contar com a vantagem numérica, os naturais do Nordeste compuseram o que pode ser denominado "grupo pioneiro" da ocupação não índia. Junto aos militares, desbravaram o lavrado e a floresta, seguindo um padrão semelhante ao de outras áreas amazônicas. São com o Nordeste que, até os dias de hoje, se estabelecem expressivas redes de contato e interação, tanto no que toca à vinda de novos migrantes, quanto na resignificação de elementos culturais há muito estabelecidos.

Segundo Aimberê Freitas - escritor e político natural de Roraima, um "filho da terra" - devido à histórica entrada de nordestinos em Roraima "este estado está se nordestinando". Guardando as devidas proporções, já que baseia sua afirmação na observação informal de quem sempre viveu em Roraima, Freitas argumenta que o sotaque característico do Nordeste está "presente nas repartições públicas, nas salas de aula, através dos professores, nas conversas do dia-a-dia, enfim, em todos os lugares". Destaca a sua importância no comércio da capital quando diz: "A avenida Jaime Brasil poderá muito bem trocar de nome, passando-se a ser chamada de Avenida Ceará, tantos são os cearenses que fazem dessa importante artéria de Boa Vista, um logradouro comercial, por excelência ...”. Informa que “dos 15 primeiros governadores de Roraima, 60\% foram nordestinos" e que junto com eles vieram conterrâneos a fim de ocupar cargos públicos e tentar a vida na região. Reafirma que a influência nordestina no estado é marcante, quando vaticina que existem "basicamente dois tipos de descendentes, os filhos dos nordestinos e os filhos dos nativos", todos, porém, carregam a "herança sócio-cultural familiar, de acordo com a origem" (FREITAS, 1998, p. 124).

Seguindo esse caminho, mas sem correr o risco de fazer afirmações peremptórias, verifica-se que as marcas da cultura nordestina estão por todos os lados, ressaltando que é possível observar também diferenciações entre os vários grupos migrantes nordestinos. Não obstante, um grupo deve ser destacado, os maranhenses. Estes formam o maior contingente migratório específico nas últimas décadas e, em tempos recentes, sua chegada é associada aos 
expedientes políticos relacionados à transformação de Roraima em estado e para o aumento do número de habitantes e de eleitores, prática imputada à corrente política do ex-governador Ottomar de Souza Pinto. Os bairros Pintolândia I, II, III e IV, criados no início dos anos de 1990, e então localizados na periferia de Boa Vista, como o nome indica, foram construídos pelo político para abrigar as levas de migrantes que chegavam à capital, sendo tradicionais redutos maranhenses na cidade.

Além disso, o maranhenses estão presentes por todas as áreas rurais do estado, sendo notória a sua presença nos municípios localizados na área sudeste do estado, as margens da rodovia Perimetral Norte (BR-210), em outras áreas de assentamento. Freitas chama a atenção para o fato de que na feira do produtor rural de Boa Vista (que centraliza a venda do produtor ao consumidor) é "o lugar onde se encontram em maior número os maranhenses" (FREITAS, 1998, p. 124). Dados demográficos permitem constatar que os maranhenses sempre migraram para a Amazônia e para Roraima, contudo, nas últimas quatro décadas estes números cresceram sobremaneira. Em um projeto de pesquisa coordenado por nós entre os anos de 2005-2006 em três bairros da capital, constatamos que mais da metade dos migrantes pesquisados eram naturais do Maranhão (SOUZA; SILVA, 2006, p. 47).

Isto talvez explique o fato observável com facilidade na sociedade boavistense: várias situações de discriminação dos maranhenses, considerados como inferiores entre os próprios nordestinos e pelos demais grupos migrantes. A eles são imputadas características "negativas", como baixa escolaridade e baixo nível técnico profissional, pouca politização, falta de recursos, avidez por benefícios que, observados sem o filtro do preconceito, são inerentes a muitos migrantes.

A longevidade da presença nordestina em Roraima pode, de certa forma, explicar a essa prática estigmatizante. Muitos dos roraimenses de nascimento, e que fazem parte das familias tradicionais e da elite econômica local, são descendentes de antigos migrantes nordestinos em segunda, terceira, quarta geração. Pode-se observar, então, uma certa diferenciação entre os migrantes mais recentes e os mais antigos, que arrogam a si o pioneirismo no "desbrava- 
mento" e na construção da sociedade local usados para legitimar suas opiniões, práticas e lugares de poder.

Por outro lado, outro aspecto colocado por Barros serve também para explicar as diferenciações entre os vários grupos migrantes em Roraima. Este argumenta que “a fronteira não é o repouso das velhas áreas costeiras de povoamento", fato que transforma o estranhamento inerente à fronteira em pretexto para definir situações de superioridade ética e política. O chamado “'metropolitanismo’ configura uma relação discriminatória que dá forma o conceito centro-periferia” (BARROS, 1995). Este raciocínio bipolarizado que opõe antigos/pioneiros e novos migrantes está historicamente enraizado na sociedade brasileira como um todo, constituindo-se em muitos casos em uma ideologia que justifica a dominação, a sobreposição de poderes e de status, a exclusão e a discriminação. É perfeitamente pertinente observar a presença desta lógica e destas práticas na sociedade roraimense, ainda que tão ricamente diversificada.

Essa lógica pode ser também observada nas relações entre índios e não-índios. Historicamente, a conquista do espaço regional pela sociedade não-índia envolve uma variedade de agentes, processos e estratégias que, divergindo ou convergindo dependendo das conjunturas, produziu uma nova territorialidade, que inclusive definiu uma fronteira geográfica nacional no extremo norte. Observando a questão historicamente vemos que se para a garantia da posse da região e para a demarcação desta fronteira a presença de grande número de indígenas foi a "solução", hoje, se constituem em um grande "problema" (FARAGE, 1991; SANTILLI, 1994).

Em nível do senso comum, essas questões que opõem os indígenas à sociedade envolvente, e que englobam o cultural, o social, o político e o econômico, no geral vem eivadas de preconceitos. Na sociedade roraimense, o indígena ocupa a base da pirâmide social, e a ele são atribuídas conhecidas características negativas: são preguiçosos, indolentes, amigos da rede e do álcool, são manipuláveis, subservientes e pouco afeitos à autoridade, não primam pelo asseio e pela aparência pessoal, sendo considerados "feios". Deve-se levar em conta, também, que este discurso acerca da inferioridade dos indígenas não é privativo de Roraima, mas tem raízes históricas e está disseminado em todo o Brasil. 
$\mathrm{Na}$ contramão da exclusão e do preconceito, nos dias de hoje os povos indígenas de Roraima lutam pelos seus direitos e estão organizados em várias entidades. Todas elas buscam reconhecimento e a estruturação e a instauração de práticas e ações que promovam a reconstrução de elementos da cultura ancestral, tais como a língua. Outro aspecto importante é a luta pela posse da terra com autonomia, fato que mexe com questões espinhosas que afetam tanto o setor público quanto o privado, como vimos no recente processo de demarcação em área contínua da Terra Indígena Raposa Serra do Sol. Em Roraima grandes querelas e embates políticos ocorrem em torno da questão da luta dos povos indígenas pelos seus direitos; da mesma forma, os indígenas se constituem, hoje, na parcela mais solidamente organizada do movimento social no estado.

Pensando os contatos entre indígenas e migrantes na atualidade, Barros observou que nos contatos entre índios e colonos nos núcleos de colonização, o migrante nordestino, que estava na base da pirâmide social no seu lugar de origem, encontra em Roraima alguém que socialmente está "abaixo" dele, o índio, visto que o colono, ainda que pobre, identifica-se como o "branco", o colonizador, ou seja, historicamente aquele que impõe a cultura (BARROS, 1995). Para o migrante nordestino que chega a Roraima, independente de seu local de origem ou situação sócio-econômica e do desenrolar do seu processo de colocação, um aspecto já está claramente dado, a definição da inferioridade dos indígenas.

Como foi visto acima, seja para os maranhenses ou para os indígenas, estes não são epítetos novos, são apenas repetições e adaptações de um discurso que, nos processos de interação, de encontro/desencontro, visa demarcar superioridades e inferioridades, lugares de poder, territorialidades. Veremos que no dia a dia do migrante essas relações complexas se expressam de formas variadas e criativas, como forma de reinventar a vida e reinventar-se como pessoa.

\section{O cordel "Roraima: terra bendita"}

A fim de pontuar esta discussão, apresentamos uma breve leitura do cordel "Roraima, Terra Bendita", de Otaniel Mendes de Souza (2009). 
O autor, que, no ano de 2008, também publicou o livreto de cordel "Vida de Cutião”, é natural de São José das Curicas, zona rural do município de Vitorino Freire, no Maranhão, e vive na vila Central, município de Cantá, Roraima.

Em entrevista concedida à Nogueira, em abril de 2011, Otaniel explica que já andou por vários lugares: sua primeira passagem por Roraima se deu em 1970, onde ficou até 1978, quando por uma desilusão amorosa migrou para Rondônia, retornando apenas em 1982. Sua primeira migração foi aos três anos de idade, quando a família migrou para Pindaré-Mirim, para trabalhar na produção de tiquira, uma aguardente feita de mandioca, motivada pela expansão das fazendas que engoliu os pequenos produtores, sufocou a produção e estrangulou o mercado de trabalho na sua região natal. A partir dai recorda a sua trajetória e, luz da lembrança dos deslocamentos empreendidos, afirma que “o nordestino vive buscando melhorar de vida, e a vida dele é buscar". Segundo Nogueira, para o cordelista, "entre as idas e vindas, Roraima se constituiu na terra bendita, o lugar dos sonhos e da segurança” (NOGUEIRA, 2011, p. 54-55)

O livreto Roraima: terra bendita parece se inscrever em outra fase da vida do autor, ao contrário do anterior, no qual cantou as agruras e desilusões dos assentados em Roraima. Maior em número de páginas - este tem 29, o anterior, tem 10 páginas - o texto revela um homem solto ao escrever e otimista para falar sobre a realidade vivida em Roraima. O próprio título anuncia o tom de exaltação do texto, um tanto laudatório e ufanista, em uma edição bem cuidada, que conta com agradecimentos, apresentação, dedicatória e prefácio e, ainda, com a chancela do SESC/RR e da XIX Feira de Livros do SESC, Federação das Indústria de Roraima-FIERR, dentre outros patrocínios. Nos dois primeiros conjuntos de versos inicia se referindo ao Brasil e ao Norte: "No norte do Brasil / Encontramos coisas sem fins (sic) / Saindo Rio Branco Acre / Chegando a Tocantins / Passando pelo Pará / Encontramos o Boi Bumbá / Nas terras de Parintins" (SOUZA, 2009, p. 5).

A partir daí se dedica a cantar Roraima, partindo da fronteira norte - na qual o estado confina com a Venezuela - passeando por muitas áreas do estado. Enumera os lugares emprestando-lhes características: "Encontramos Pacaraima/Com seus bonitos lavrados"; É também no Jundiá/Que existe 
barreira"; "Rorainópolis: uma cidade/De crescimento constante"; É São João da Baliza/Lá tem muito produtor; "Caroebe é muito bom/É a terra da banana". Sem fazer distinções político-administrativas, entre cidades, vilarejos ou simples povoados, imprime nos lugares por onde seus versos passam marcas identificadoras. Cada lugar anotado pelo poeta ganha um adjetivo elogioso quase sempre.

Não obstante, o texto é pontuado por versos que podem ser traduzidos como comentários afinados com a conjuntura regional da época em que o texto foi produzido e, também, com as parcerias estabelecidas pelo autor: "Tem muita gente estrangeira / De olho em nossa riqueza / Com muito ouro e diamante / E nós vivendo na pobreza / Se não prestar atenção / Vamos acabar na mão / Da burguesia inglesa (SOUZA, 2009, p. 13).

Este e cinco conjuntos de versos que o seguem tratam do mesmo tema: a cobiça estrangeira pela Amazônia e por Roraima em especial. É bom lembrar que este foi um período de intensa polarização política e ideológica em Roraima, em função da demarcação em área contínua da Terra Indígena Raposa Serra Sol, cujo processo redundou na retirada de todos os não índios da área, e mexeu sobremaneira com os interesses dos grandes fazendeiros de arroz que lá atuavam, fato que mobilizou a elite política e econômica local contra esta demarcação. Um dos eixos principais do discurso que fundamentava este movimento era aquele que alertava para a existência de poderosos interesses internacionais por trás da demarcação. Esse discurso teve uma repercussão muito grande na sociedade local, notadamente entre aqueles que viviam da terra, grandes e pequenos. E foi repetido à exaustão pelos meios de comunicação e em todos os espaços onde se abordava o assunto, partidários de ambas as posições levavam a cabo discussões acaloradas e Seu Otaniel entra neste circuito: “Tem muitas ONGs estrangeiras / Com grande área de terra / Pra tomar nossa Amazônia / Eles fazem até guerra / Mas nós vamos expulsar / E não deixar mais entrar / Este papo se encerra" (SOUZA, 2009, p. 13). De maneira explicita os versos de Seu Otaniel repercutem este momento e o autor, como tantos outros, toma posição: "Depois que apareceu / Estrangeiro interessado / Que índio tem que viver / Em território isolado / Daí começou a crise / Assim que os índios dizem / O estrangeiro culpado" (SOUZA, 2009, p. 26). 
Neste sentido, Guillen se refere ao poeta de cordel como "um grande narrador da vida cotidiana nordestina", alguém que toma posição sobre o que narra (GUILLEN, 2002), ele é um comentador que utiliza as palavras com habilidade. A forma como o cordel é composto nos leva a encará-lo como um texto espontâneo, tributário da oralidade rimada, embora, por excelência, fundamente-se na arguta observação social, na crítica, observando-se o engajamento radical às temáticas postas à sociedade no calor da hora.

Observa-se, no entanto, que a espontaneidade e a agilidade do cordel não implicam a ausência de objetivos bem definidos a serem veiculados. As temáticas se vinculam aos seus autores e àquilo que o cerca, este é o mote para compor os versos, falar do local e do cotidiano. Pontua o seu "passeio" pelos lugares roraimenses, enumerando também as suas gentes: "Gente do Brasil inteiro / Pode prestar atenção / Tem gente do Paraná / E também do Maranhão / Tem paulista e capixaba / Sulista que não se acaba Grande miscigenação" (SOUZA, 2009, p. 7). Fala da diversidade de gentes, ou seja, dos muitos migrantes: "Tem gente de toda parte / Deste Brasil de meu deus / Maranhense e cearense / Descendente de europeu / De gente que mora ali / Estou dizendo para ti / Tem gente até dos zezéus" (SOUZA, 2009, p. 11). Gentes diversas como ele, Otaniel, vindas de muitos lugares e que ocupam e fazem de Roraima o seu lugar.

Neste "passeio" que faz por Roraima, o autor o faz com familiaridade e benevolência, e falando também sobre o que mexe com a sociedade. Como vimos acima, a mensagem é que cada canto de Roraima oferece algo que pode ser apreciado, que merece ser destacado e enaltecido, um lugar tão valioso e especial que é alvo de cobiça e de disputas. O conjunto destas partes forma Roraima, a terra bendita concebida pelo autor e que encabeça o título. Isto nos leva a ressaltar novamente que mudanças se operaram na vida de Otaniel e na forma como ele se coloca em Roraima. Se no primeiro livreto é possível observar um homem encerrado em uma realidade restrita - aquela do campo e do lote - comandada por um ciclo natural do amanhecer ao anoitecer, dos dias e das semanas, contada com laivos de amargura e certo desencantamento, no segundo, vemos um homem livre, que "sobrevoa" um espaço amplo, que se apropria da área estadual, que conta o que vê de forma dinâmica e otimista. 
Muda a temática, o que não é novidade para a literatura de cordel, dinâmica e pautada em temas do cotidiano e próximos dos autores; muda também a forma de escrever e de abordar lugar que foi adotado pelo autor. Fica patente houve uma mudança na relação do autor com Roraima, ou melhor, na maneira como Otaniel vê Roraima e se vê neste lugar onde vive: "Roraima é terra boa / Assim está na escrita / Todos que chegam aqui / É claro que acredita / E logo que vem chegando / Chega pulando e gritando / Roraima terra bendita" (SOUZA, 2009, p. 27). Isto nos leva a pensar no que diz Haesbaert, que os espaços expressam muito mais do que a sua manifestação concreta, pois neles há "territórios (enquanto espaços concreta e/ou simbolicamente dominados/ apropriados) de um caráter particular, especial, cuja significação extrapola em muito seus limites físicos e sua utilização material (HAESBAERT, 2002, p. 149).

Seu Otaniel, como é conhecido, se apropria do espaço onde vive e faz uma leitura simbólica dele por meio da poesia de cordel, ao ver-se e ao se colocar como migrante nordestino, como maranhense e como roraimense: "Eu sou feliz não importa / Aquilo que alguém pense / Quem me conhece sabe / Que eu sou maranhense / Eu só quero ser feliz / Até brigo com que diz / Que eu não sou roraimense" (SOUZA, 2009, p. 27). Neste texto a mensagem que nos passa é de integração, de inserção, pacificado se levarmos em consideração o livreto anterior.

Assim, como argumenta Silva, na leitura que faz das ideias de Stuart Hall, na contemporaneidade, as identidades são "multiplamente construídas ao longo dos discursos, práticas e posições que podem se cruzar ou ser antagônicos". Exposta a uma historicização radical, a identidade estaria "constantemente em processo de mudança e transformação" (SILVA, 2000, p. 108). E os processos migratórios ensejam transformações naquilo que se é, na maneira como o indivíduo se vê e se coloca no mundo; define também as formas empregadas para explicar e compreender a sua trajetória, ou seja, o quê o migrante fala e como fala.

$\mathrm{O}$ autor lança mão de uma forma socialmente reconhecida para falar de si e do mundo que o cerca. A bagagem cultural migrante do autor ancorada em Roraima torna este lugar de adoção um "espaço de referência 
identitária" (HAESBAERT, 2002, p. 149) para o cordel, ele mesmo manifestação legítima e legitimada da cultura popular brasileira e de uma nordestinidade instituída. Esta, somada ao talento e a habilidade de Otaniel com as palavras e as rimas, imprime no autor uma identidade nordestina, mas também maranhense e roraimense, sem prejuízos ou aparentes hierarquizações ou, ainda incômodas fraturas. Ele é e pronto!

Seguindo este raciocínio, considera-se que muito há para dizer sobre Roraima e seu processo de ocupação humana, mas certo é que este ainda está em franco desenrolar, tanto no que toca à ocupação do seu espaço físico, quanto à configuração de suas espacialidades e territorialidades, principalmente constatada a importância histórica das migrações. Neste aspecto, ainda que se considere a afirmação de Freitas de que Roraima é um estado "nordestinado" polêmica e excessivamente peremptória e generalista, a presença nordestina em Roraima é um importante elemento mediador das trocas culturais e da construção identitária do lugar e das gentes roraimenses.

\title{
Notes ON THE NORTH-EASTERN BRAZILIAN PRESENCE IN RORAIMA
}

\begin{abstract}
The Brazilian Amazon is a place of migrants, of the many and diverse people who pursue, in the region, the dream of an earthly heaven and of a land with endless treasures. Similarly to other Amazon areas, the migrants that arrive in Roraima are motivated by various circumstances, influenced in turn by socio-economic conjunctures that have historically approximated the North-East and the North of Brazil. The constant influx of nordestinos in the Amazon and in Roraima produces cultural exchanges and generates modes of existence and specific representations of the experience of the migration and the integration, manifested in various practices and presented in various forms of cultural production. This work discusses the North-Eastern Brazilian presence in Roraima, in light of some possible approximations: North-East/North-Easts, NorthEast/Roraima. More specifically, this work presents an analysis of the cordel "Roraima terra bendita” (2009), by Otaniel Mendes da Souza, an author from the state of Maranhão, who is based in Roraima since 1982.
\end{abstract}

KEYWORDS: Roraima. Amazon. Cordel Literature. Migrants. North-East. 


\section{Referências}

ALBUQUERQUE JR, D. M. A invenção do Nordeste e outras artes. Recife/São Paulo: Fundação Joaquim Nabuco/Cortez, 1999.

ALBUQUERQUE JR, D. M. A feira dos mitos: fabricação do folclore e da cultura popular (Nordeste 1920-1950). São Paulo: Intermeios, 2013.

BARROS, N. C. C. Roraima: paisagens e tempo na Amazônia setentrional. Recife: Editora Universitária (UFPE), 1995.

FARAGE, N. As Muralhas do Sertão: Os Povos Indígenas no Rio Branco e a Colonização. Rio de Janeiro: Paz e Terra/ANPOCS, 1991.

FREITAS, A. Geografia e História de Roraima. Boa Vista, 1998.

GUILLEN, I. C. M. Cantadores das viagens. a literatura de cordel e a experiencia da migração nordestina para a Amazônia. 2002.

HAESBAERT, R. Des-territorialização e identidade: a rede "gaúcha" no Nordeste. Niterói: EDUFF, 1997.

HAESBAERT, R. Território Alternativos. Niterói/São Paulo: EDUFF/Contexto, 2002.

LACERDA, F. G. Entre o sertão e a floresta: natureza, cultura e experiências sociais de migrantes cearenses na Amazônia (1889-1916). Revista Brasileira de História. São Paulo, v. $26, n^{\circ} 51$, p. $197-225-2006$.

MAGALHÃES, M. G. S. D. Amazônia: o extrativismo vegetal no sul de Roraima: 19431998. Boa Vista: EdUFRR, 2008.

NOGUEIRA, F. M. M. O lugar e a utopia: história e memórias de migrantes nordestinos em Roraima (1980 a 1991). 2011. 74p. Trabalho de Conclusão de Curso (Graduação) Curso de História, Universidade Federal de Roraima. Boa Vista, 2011.

OLIVEIRA, A. Integrar para não entregar: políticas públicas e a Amazônia. 2.ed. São Paulo: Papirus, 1991.

OLIVEIRA, R. G. A herança dos descaminhos na formação do estado de Roraima. 2003. Tese (Doutorado em História Social), Faculdade de Filosofia, Letras e Ciências Humanas, Universidade de São Paulo. São Paulo, 2003.

SANTILLI, P. As Fronteiras da República. História e política entre os Macuxi no Vale do Rio Branco. São Paulo: USP/FAPESP, 1994.

SANTOS, N. P. D. Política e poder na Amazônia: o caso de Roraima (1970 e 2000). Boa Vista: EdUFRR, 2013.

SOUZA, C. M. Gaúchos em Roraima. Porto Alegre: EDIPUCRS, 2001.

SOUZA, C. M. Roraima e as migrações. Textos e Debates (UFRR), v. 9, p. 257-271, 2005.

SOUZA, C. M. \& SILVA, R. G. Migrantes e Migrações em Boa Vista: os bairros Senador Hélio Campos, Raiar do Sol e Cauamé. Boa Vista: EDUFRR, 2006. 
Carla Monteiro de Souza, Francisco Marcos Mendes Nogueira

SOUZA, O. M. Vida de Cutião. Boa Vista, 2008.

SOUZA, O. M. Roraima: terra bendita. Boa Vista, 2009.

VALE, A. L. F. O “Ceará” em Roraima - migração de cearenses: 1980-1999. Jaboticabal/ SP: FUNEP, 2005.

VALE, A. L. F. Migração e Territorialização: as dimensões territoriais dos nordestinos em Boa Vista/RR. 2007. 268 p. Tese (Doutorado em Geografia Humana) - Faculdade de Ciências e Tecnologias, Universidade Estadual Paulista, Presidente Prudente, 2007.

Data de recebimento: 10/07/2014

Data de aceite: 20/09/2014 